\title{
Irrational Anti-Retroviral Therapy Prescription among Children Under 15 Years in Eastern Uganda
}

\author{
Mulema VS ${ }^{*}$, Lukabwe $\mathrm{I}^{2}$, Niyonzima $\mathrm{N}^{3}$, Akena $\mathrm{D}^{4}$, Elyanu $\mathrm{P}^{5}$ and Nakiyingi-Miiro $\mathrm{J}^{6}$ \\ ${ }^{1}$ HIV Access Program, Clinton Health Access Initiative, Kampala, Uganda \\ ${ }^{2}$ Pediatric HIV Unit, STD/AIDS Control Program, Ministry of Health, Kampala, Uganda \\ ${ }^{3}$ Uganda Cancer Institute, Kampala, Uganda \\ ${ }^{4}$ Department of Psychiatry, Makerere University, Kampala, Uganda \\ ${ }^{5}$ University of Texas, School of Public Health, Houston, USA \\ ${ }^{6} \mathrm{MRC/UVRI} \mathrm{Uganda} \mathrm{Research} \mathrm{Unit} \mathrm{on} \mathrm{AIDS,} \mathrm{Entebbe,} \mathrm{Uganda}$
}

*Corresponding author: Mulema VS, HIV Access Program, Clinton Health Access Initiative, Kampala, Uganda, Tel: +256772531222, E-mail: vivmulema@gmail.com

Citation: Mulema VS, Lukabwe I, Niyonzima N, Akena D, Elyanu P, et al. (2017) Irrational Anti-Retroviral Therapy Prescription among Children Under 15 Years in Eastern Uganda. J Aids Hiv Infe 3(1): 104

Received Date: October 16, 2016 Accepted Date: June 20, 2017 Published Date: June 24, 2017

\begin{abstract}
Background: Highly Active Anti-Retroviral Therapy (HAART) has transformed HIV/AIDS into a manageable chronic illness with HIVinfected children having near-normal growth milestones as a result of virologic control and immunologic reconstitution. However, for HAART to be beneficial, it needs to adhere to standard guidelines. Prescribing HAART for children is complex and there is little information available on prescription patterns for children in Africa. This study aimed to determine the prevalence of irrational prescriptions, describe the types of errors and identify the factors associated with these errors.

Methods: We conducted a retrospective chart review of children receiving HAART from April 2013 to September 2013 at two hospitals in East Central Uganda. Prescriptions for children aged 0 to 15 years, health facility inventory and stock documents were reviewed.

Results: We assessed 166 children. Of these, $58 \%$ had at least one irrational prescription. Errors of commission, majority of which (57\%) related to prescription of adult formulations, were the most predominant comprising $83 \%$ of all errors. Errors of omission, all of which concerned missing weight, constituted $11 \%$. Integration errors (6\%) included regimens that were not HAART (3\%). Laboratory investigations such as CD4 and hemoglobin counts were not done at the frequency recommended by treatment guidelines. Being on treatment for less than a year; $\mathrm{OR}=14.07$ (95\% CI: 2.746-72.085), P-value $=0.002$ and receiving care from a private facility; $\mathrm{OR}=2.68(95 \%$ CI: 1.282-5.599), P-value $=0.009$ were associated with receiving at least one irrational prescription.

Conclusion: The prevalence of irrational prescriptions is high among children in Uganda. Children receiving care in private health facilities and those newly initiated on treatment are at particularly high risk of receiving these prescriptions. Quality improvement strategies such as clinical audits, mentorship and automated prescribing systems should be implemented to mitigate their occurrence.

Keywords: Prescription errors; Children; Anti-Retroviral Agents; Cross- sectional studies; Retrospective studies

List of Abbreviations: AIDS: Acquired Immune Deficiency Syndrome; ARV: Anti-retroviral; FDC: Fixed Dose Combination; HAART: Highly Active Anti-retroviral Therapy; HIV: Human Immunodeficiency Virus; PMTCT: Prevention of Mother to Child Transmission; TB: Tuberculosis
\end{abstract}

\section{Introduction}

HIV/AIDS has had a significant impact on mortality worldwide since the epidemic began [1]. In 2014 alone, 1.2 million people died due to AIDS-related causes worldwide. Sub-Saharan Africa has been disproportionately affected with $66 \%$ of new infections and deaths occurring in the region [1]. Uganda has approximately $6 \%$ of the total number of children living with HIV worldwide and contributed almost 3\% to new pediatric infections in Sub-Saharan Africa in 2014 [2-4].

Dramatic gains in survival have, however, been attained using Highly Active Anti-retroviral Therapy (HAART), a combination of medicines that reduces the rate of replication of HIV and halts its progression into AIDS. When used optimally, HAART has been shown to improve growth virologic and immune responses in children [5-8] thereby reducing morbidity and mortality [9]. Between 2004 and 2011, the estimated number of children who died from AIDS-related causes decreased by almost 30\% worldwide largely as a result of HAART $[10,11]$. 
For HAART to remain clinically effective throughout the lifetime of the patient, prescribers need to adhere to standard treatment guidelines. The World Health Organization (WHO) states that failure to prescribe according to guidelines is regarded as irrational use of medicines, and recommends their appropriate use as a strategy to improve patient outcomes, reduce the incidence of adverse drug reactions and decrease health care costs $[12,13]$. Rational drug use is defined as 'Patients receive medications appropriate to their clinical needs, in doses that meet their own individual requirements, for an adequate period of time, and at the lowest cost to them and their community' [14]. In order to ascertain the existence of irrational prescribing, a standard is required to outline the most optimal algorithms for medicines use [15]. At the time this study was conducted, Uganda was implementing HAART under 2012 national guidelines [16].

Prescribing HAART for children is complex. Attention must be paid to age, weight bands, CD4 counts and history of Prevention to Mother to Child Transmission (PMTCT) uptake, WHO staging as well as co-infections like Tuberculosis (TB). With all these factors to consider, there is considerable room for error [16-18].

Irrational use of HAART is associated with a number of negative effects including adverse drug reactions, drug resistance, treatment failure and higher chances of mortality [19-21]. Children are more prone to harm from irrational medicines use stemming from their under-developed renal and hepatic drug clearance systems [22]. Furthermore, 25\% higher costs are experienced by patients with an irrational prescription for HAART as compared to those with rational prescriptions [23].

There is currently little information available on prescription patterns of HAART in Sub-Saharan Africa where over 85\% of new infections in children occur [1,3]. This study sought to determine the extent of irrational prescribing of HAART in children under 15 years in East Central Uganda, describe the types of irrational prescriptions and assess the factors associated with these practices.

\section{Methods}

\section{Study Design}

This retrospective cross-sectional study was conducted at TASO Jinja, a private not-for-profit facility and Iganga hospital, a public hospital in East Central Uganda. The clinic charts of children aged less than 15 years who received at least four prescriptions for HAART between April 2013 and September 2013 were reviewed. This ensured that all patients received an average to maximum number of prescriptions and hence relatively equal risk of exposure to existing prescribing practices. Exclusion criteria included children who received less than four prescriptions, those who turned 15 before they received the four prescriptions and those without a prescriber signature for any prescription in the timeframe. Facility inventory lists and stock cards were reviewed to assess the availability of equipment, reagents and medicines.

Ethical approval was obtained from TASO and London School of Hygiene and Tropical Medicine Institutional Review Committees, and Uganda National Council of Science and Technology.

\section{Sampling}

The active number of children on HAART as of December 2013 for each of the two facilities was obtained; 259 at TASO Jinja and 150 at Iganga hospital. The sample size was determined using the Leslie- Kish formula and the sampling unit was a patient. The total sample size generated was 246 children using a population prevalence of $20 \%$. Studies in resource-rich countries had shown this to range from $4 \%-10 \%$ [24,25]. It was anticipated that this prevalence would be higher in resource-limited settings. A finite population correction factor was incorporated due to the small number of already existing pediatric patients from which the sample was drawn. This yielded 154 patients. An additional 10\% patient was included to cater for any patient charts that had missing information and were subsequently excluded. A total of 169 children were therefore evaluated in the study. Using proportionate sampling based on the original patient numbers as of December 2013, a representative sample of active children per facility was determined from the total sample. TASO Jinja had 107 children while Iganga hospital had 62 children. Systematic sampling using the $\mathrm{K}^{\text {th }}$ factor was then used to select the patient files whose prescriptions were reviewed. All prescriptions received by each child in the study period were assessed.

\section{Data collection}

Exposure variables were in two categories: Patient-related factors included age, gender, weight, PMTCT history, TB status and were derived from patient files while facility-related factors included the ownership, patient load, availability of medicines and equipment. These were extracted from stock cards, facility equipment inventory and the HAART register.

\section{Analytical approach}

Error definition: Khalid et al postulated three major types of medication errors derived from Ferner and Aronson's psychological approach [26,27]. The types of irrational prescriptions were extrapolated from this study. Errors of commission were defined as errors related to indication of wrong information about a drug such as wrong strength, frequency and duration. Errors of 
integration were 'knowledge-based errors' due to a prescriber's inability to incorporate complementary information about the patient and/or the drug to formulate an appropriate prescription. Errors of omission were categorized as 'absent, vagueness, incompleteness or illegibility of any component of the body of a prescription' [26]. Prescriptions were coded into rational and irrational prescriptions according to the treatment guidelines.

Statistical analysis was done using STATA version 12 (StataCorp. College Station, Texas. 1985). The association between irrational prescription and the exposure variables was examined using crude Odds Ratios (ORs) and their 95\% Confidence Intervals (95\% CI). These associations were tested for statistical significance using the Pearson Chi-square test with a 5\% level of significance denoting a statistically significant association. Logistic regression was used to assess the association between prescribing practice and independent risk factors.

\section{Results}

\section{Patient characteristics}

Data was collected from 62 children in Iganga hospital and 104 in TASO Jinja. A total of 890 prescriptions were obtained from the 166 children over the 6 months making an average of five prescriptions per child. Table 1 shows the characteristics of these children. The median age was 5 years with an interquartile range of 2 to 7 years. Only $12(7 \%)$ of these patients had newly initiated HAART within the study period. A total of 96 (58\%) children did not have a CD4 test done in the review period and these made up the majority in each age category. $2 \%(n=4)$ of children were co-infected with TB while $4 \%(n=7)$ had previously been exposed to PMTCT.

\begin{tabular}{|c|c|c|}
\hline Variable & Frequency & Percentage (\%) \\
\hline \multicolumn{3}{|l|}{ Sex } \\
\hline Male & 70 & 42 \\
\hline Female & 96 & 58 \\
\hline \multicolumn{3}{|l|}{ Age (years) } \\
\hline$<2$ & 34 & 21 \\
\hline 2 to $<5$ & 40 & 24 \\
\hline 5 to $<15$ & 92 & 55 \\
\hline \multicolumn{3}{|l|}{ Type of patient } \\
\hline New & 12 & 7 \\
\hline Existing & 154 & 93 \\
\hline \multicolumn{3}{|c|}{ CD4 (most current CD4 within the review period) } \\
\hline \multicolumn{3}{|l|}{$<2$ years } \\
\hline$<750$ & 3 & 9 \\
\hline$>=750$ & 6 & 18 \\
\hline Missing CD4 & 25 & 74 \\
\hline \multicolumn{3}{|l|}{2 to $<5$ years } \\
\hline$<750$ & 8 & 20 \\
\hline$>=750$ & 9 & 23 \\
\hline Missing CD4 & 23 & 58 \\
\hline \multicolumn{3}{|l|}{5 to $<15$ years } \\
\hline$<350$ & 12 & 13 \\
\hline$>350$ & 32 & 35 \\
\hline Missing CD4 & 48 & 52 \\
\hline \multicolumn{3}{|l|}{ TB co-infection } \\
\hline Yes & 4 & 2 \\
\hline No & 162 & 98 \\
\hline \multicolumn{3}{|c|}{ Previous PMTCT exposure } \\
\hline Yes & 7 & 4 \\
\hline No & 159 & 96 \\
\hline
\end{tabular}

Table 1: Baseline characteristics of children under 15 years on HAART at TASO Jinja and Iganga hospital in East Central Uganda between April and September 2013 


\section{Facility characteristics}

TASO had a total of 6,035 patients while Iganga had 1,844. There were 38 prescribers (27 in TASO and 11 in Iganga) for all 890 prescriptions. Current HAART guidelines were available and accessible in both health centers and they each had a pediatric weighing scale and a hemoglobinometer. While Iganga hospital had an in-house CD4 machine, TASO relied on the national sample transportation system to the nearest laboratory hub to access CD4 testing. This hub is located about half a kilometer from TASO within the same hospital complex and therefore was not significantly far from the point of care to impede service delivery.

With regard to medicines, both Iganga and TASO reported a stock out of only one formulation each; (Abacavir/Lamivudine 60/30mg and Efavirenz 200mg respectively) during the study period. Notably, a number of recommended pediatric formulations had never been carried as products by TASO including Nevirapine 50mg, Lopinavir/ritonavir 80/20mg/ml and Abacavir 60mg.

\section{Prevalence of irrational prescriptions}

Of all children in the study, 58\% ( $n=97)$ had at least one irrational prescription; $71 \%(n=69)$ from TASO and $29 \%$ ( $\mathrm{n}=28)$ from Iganga. The biggest proportion of children in Iganga hospital had only one irrational prescription (61\%) while the greater proportion of children in TASO (46\%) had two to four irrational prescriptions. A substantial proportion in TASO (39\%) also had more than four irrational prescriptions as shown in Table 2.

\begin{tabular}{|c|c|c|}
\hline Variable & Rational prescription (\%) & Irrational prescription (\%) \\
\hline Patient characteristics & & \\
\hline Sex & & $40(57)$ \\
\hline Male & $30(43)$ & $57(59)$ \\
\hline Female & $39(41)$ & $21(62)$ \\
\hline Age & & $26(65)$ \\
\hline$<2$ years & $13(38)$ & $50(54)$ \\
\hline $2-<5$ years & $14(35)$ & $12(100)$ \\
\hline $5-<15$ years & $42(46)$ & $85(58)$ \\
\hline Type of patient & & \\
\hline New & $0(0)$ & $3(75)$ \\
\hline Existing & $69(42)$ & $94(58)$ \\
\hline TB co-infection & & \\
\hline Yes & $1(25)$ & $2(29)$ \\
\hline No & $68(42)$ & $95(60)$ \\
\hline PMTCT exposure & & \\
\hline Yes & $5(71)$ & \\
\hline No & $64(40)$ & \\
\hline
\end{tabular}

Table 2: Prevalence of at least one irrational prescription for children under 15 years on HAART by patient characteristics in TASO Jinja and Iganga hospital in East Central Uganda

There was almost no difference in the proportion of children with at least one irrational prescription among the male (57\%) and female (59\%) gender. Children aged two to less than five years had the most irrational prescriptions (65\%) followed by children aged less than two years (62\%). All newly enrolled children $(n=12)$ during the review period had at least one irrational prescription.

Of the 96 children who did not have a CD4 result, 85 (89\%) were from TASO. There were four TB co-infected patients (2\%); one in Iganga and three in TASO. All the three in TASO had at least one irrational prescription whereas the one in Iganga did not have any irrational prescription. Seven (4\%) children had been exposed to PMTCT; four of these were in Iganga. None of these children had an irrational prescription while $67 \%$ of those in TASO had at least one irrational prescription.

Types of irrational prescribing: As shown in Table 3, errors of commission were the most common type of error comprising $83 \%$ $(n=260)$. In over half of these errors (57\%), prescriptions were for an adult formulation that would necessitate breaking the tablet to cater for the weight of the child. This was followed by under- or over-dosing in relation to the child's weight at 20\% ( $\mathrm{n}=62$ ).

\begin{tabular}{|c|c|c|c|}
\hline & TASO Jinja & Iganga Hospital & Overall \\
\hline Type of error and reason & Frequency (\%) & Frequency (\%) & Frequency (\%) \\
\hline Error of omission & $\mathbf{3 1 ( 8 6 )}$ & $\mathbf{5 ( 1 4 )}$ & $\mathbf{3 6}(\mathbf{1 1})$ \\
\hline No weight indicated & $31(86)$ & $5(14)$ & $36(11)$ \\
\hline Error of commission & $\mathbf{2 2 1 ( \mathbf { 8 5 } )}$ & $\mathbf{3 9 ( 1 5 )}$ & $\mathbf{2 6 0 ( \mathbf { 8 3 } )}$ \\
\hline
\end{tabular}




\begin{tabular}{|c|c|c|c|}
\hline & TASO Jinja & Iganga Hospital & Overall \\
\hline $\begin{array}{c}\text { Type of error and reason } \\
\text { Adult formulations were prescribed and tablets were } \\
\text { broken }\end{array}$ & $178(99)$ & $1(1)$ & $179(57)$ \\
\hline Dosing & $41(66)$ & $21(34)$ & $62(20)$ \\
\hline Use of a brand name & $0(0)$ & $16(100)$ & $16(5)$ \\
\hline $\begin{array}{c}\text { Scheduling } \\
\text { Adult formulations were prescribed but tablets were } \\
\text { not broken }\end{array}$ & $1(50)$ & $1(50)$ & $2(1)$ \\
\hline $\begin{array}{c}\text { Error of integration } \\
\text { Regimen not HAART }\end{array}$ & $1 \mathbf{1 1}(\mathbf{5 8})$ & $0(0)$ & $1(0)$ \\
\hline $\begin{array}{c}\mathbf{8}(\mathbf{4 2}) \\
\text { reguency (\%) }\end{array}$ & Frequency (\%) \\
\hline $\begin{array}{c}\text { No 'lead in' for new patients on Nevirapine-based } \\
\text { regimens }\end{array}$ & $4(57)$ & $3(43)$ & $8(3)$ \\
\hline Switching from second line to first line & $0(0)$ & $4(100)$ & $7(2)$ \\
\hline
\end{tabular}

Description of irrational prescriptions

Table 3: Types of irrational prescriptions of HAART and their description for children under 15 years at TASO Jinja and Iganga hospital in East Central Uganda between April and September 2013

Errors of omission were the second most common comprising $11 \%(n=36)$ of the total prescription errors. All were related to missing weight of the child.

Errors of integration were the least common making up 6\% $(n=19)$ of all prescriptions. Of these, majority were related to prescriptions that were not considered to be HAART. Seven initial prescriptions out of the twelve for new patients did not have appropriate 'lead in' dosing to reduce the likelihood of an adverse drug reaction due to Nevirapine. Only one child out of the ten initiated on Zidovudine-based regimens was given a hemoglobin test. Most notably, however, one child was prescribed a first line regimen on four occasions after having initially received a second line regimen.

Factors associated with irrational prescribing: In the multivariate analysis, prescriptions for 161 patients were assessed as five children did not have weight indicated at any of their visits. After adjusting for various factors, the odds of having an irrational prescription and having been on HAART for less than one year increased from eleven to fourteen times that of those who were on HAART for more than a year $(\mathrm{P}$-value $=0.002)$ as shown in Table 4 Children in TASO were 2.7 times more likely to have an error in at least one of their prescriptions as compared to Iganga hospital (P-value $=0.009$ ).

\begin{tabular}{|c|c|c|c|c|c|}
\hline Variable & $\begin{array}{c}\text { Number of children with } \\
\text { irrational prescriptions } \\
(\%)\end{array}$ & $\begin{array}{l}\text { Unadjusted Odds } \\
\text { Ratio } \\
(95 \% \mathrm{CI})\end{array}$ & P-value & $\begin{array}{c}\text { Adjusted Odds Ratio } \\
(95 \% \mathrm{CI})\end{array}$ & P-value \\
\hline \multicolumn{6}{|l|}{ Type of patient } \\
\hline On treatment for $>1$ year & $73(75)$ & & & & \\
\hline On treatment for $<=1$ year & $24(25)$ & $11.00(2.506-48.386)$ & $0.001^{\star}$ & $14.07(2.746-72.085)$ & $0.002^{\star}$ \\
\hline \multicolumn{6}{|l|}{ Weight } \\
\hline$\geq 35 \mathrm{~kg}$ & $6(6)$ & & & & \\
\hline $3-34.9 \mathrm{~kg}$ & $88(94)$ & $2.90(1.008-8.229)$ & $0.05^{\star}$ & $2.62(0.842-8.126)$ & 0.1 \\
\hline \multicolumn{6}{|l|}{ Sex } \\
\hline Male & $40(41)$ & & & & \\
\hline Female & $57(59)$ & $1.09(0.587-2.046)$ & 0.8 & & \\
\hline \multicolumn{6}{|l|}{ Age } \\
\hline$<5$ & $47(49)$ & & & & \\
\hline $5-<15$ & $50(52)$ & $0.68(0.365-1.279)$ & 0.2 & & \\
\hline \multicolumn{6}{|l|}{ CD4 } \\
\hline Low $(<750$ and $<350)$ & $15(35)$ & & & & \\
\hline High $(>750$ and $>350)$ & $28(65)$ & $0.78(0.278-2.217)$ & 0.6 & & \\
\hline \multicolumn{6}{|l|}{ TB Co-infection } \\
\hline Yes & $3(3)$ & & & & \\
\hline No & $94(97)$ & $0.46(0.046-4.525)$ & 0.5 & & \\
\hline \multicolumn{6}{|l|}{ PMTCT exposure } \\
\hline Yes & $2(2)$ & & & & \\
\hline
\end{tabular}




\begin{tabular}{|c|c|c|c|c|c|}
\hline Variable & $\begin{array}{c}\text { Number of children with } \\
\text { irrational prescriptions } \\
(\%)\end{array}$ & $\begin{array}{l}\text { Unadjusted Odds } \\
\text { Ratio } \\
(95 \% \mathrm{CI})\end{array}$ & P-value & $\begin{array}{l}\text { Adjusted Odds Ratio } \\
(95 \% \mathrm{CI})\end{array}$ & P-value \\
\hline No & $95(98)$ & $3.71(0.698-19.716)$ & 0.1 & $8.433(0.903-78.750)$ & 0.1 \\
\hline \multicolumn{6}{|l|}{ Health facility-related factors } \\
\hline TASO Jinja (private sector) & $28(29)$ & & & & \\
\hline Iganga Hospital (Public sector) & $69(71)$ & $2.39(1.256-4.561)$ & $0.008^{*}$ & $2.68(1.282-5.599)$ & $0.009^{*}$ \\
\hline
\end{tabular}

${ }^{*}$ P-value significant at $\mathbf{P}=\mathbf{0 . 0 5}$

Factors associated with irrational prescriptions

Table 4: Association of patient-related and health facility-related characteristics with number of children under 15 years on HAART who received at least one irrational prescription at TASO Jinja and Iganga hospital in East Central Uganda between April and September 2013

\section{Discussion}

This study was aimed at determining the prevalence of irrational HAART prescriptions among children aged less than 15 years, characterizing the types of irrational prescriptions as well as identifying any factors that could be associated with these errors.

Slightly over half of the children (58.4\%) had received at least one irrational prescription. Of these, $71.1 \%$ were from the private facility - TASO. All new patients within the study period had at least one irrational prescription. Errors of commission were the most common type of error accounting for $83 \%$ of all irrational prescriptions. These were predominantly about formulations that were not appropriate for the age of the child. Errors of omission were all related to missing weight and were the next most common in occurrence constituting $11 \%$. Errors of integration, largely regarding regimens that were not considered to be HAART, made up only $6 \%$ of the total burden of errors. Being on treatment for less than a year; OR=14.07 (95\% CI: 2.746-72.085), P-value $=0.002$ and receiving care from a private facility; OR=2.68 (95\% CI: 1.282-5.599), P-value $=0.009$ were associated with receiving at least one irrational prescription.

There has been very little investigation of HAART prescribing patterns and virtually none in Sub-Saharan Africa. Review of literature highlighted twenty four papers that were directly related to prescribing HAART according to guidelines. Of these, only one study was conducted specifically among children in the United Kingdom [28]. To our knowledge, this has been the first attempt to document HAART prescription patterns for children in Africa.

\section{Prevalence of Irrational Prescriptions}

The proportion of children with irrational prescriptions was six to thirteen times higher than that encountered in three other studies $[24,25,29]$. However, two of these studies addressed essential medicines and were conducted in developed countries. It is expected that the prevalence rates would be lower in higher income countries given the level of resources available to implement quality care programs. However, these results also suggest that prescribing essential medicines is easier than ARVs. No study made this comparison in our literature review.

Two of the above studies had prolonged follow up times of two and four years and went further on to intervene when there were errors noted in the prescription making it possible that prescribers became more careful at prescribing over time and hence the lower error rates observed $[24,29]$. The timeframe covered in the cross-sectional study was also short at one week as compared to the 6 months that were investigated in this study potentially yielding fewer irrational prescriptions [25].

\section{Types of Irrational Prescriptions}

Errors of commission have been documented in this study as the most common type of error. Previous studies have indicated that errors of omission are higher [26,30,31]. It would be expected that this study would have similar results as Khalid et al as both were observational studies conducted in primary care settings without any intervention by pharmacists. However, this was not the case probably because standardized templates from the Ministry of Health in Uganda are available to guide prescribers on information that must be written on the prescription. Van Rosse et al. showed that tools that required minimal cognitive processing by prescribers such as 'Computerized Physician Order Entry' (CPOE) systems reduced errors [32].

This study documented that children were still being prescribed adult formulations despite the fact that pediatric Fixed Dose Combination (FDC) formulations were introduced in Uganda in 2008 [33]. A probable cause for this was gaps in the support supervision and mentorship processes for prescribers.

While scheduling was a challenge in other studies with error rates ranging between $16.6 \%$ and $28.3 \%$ [26,29,34], this type of error only constituted $1 \%$ of the total number of irrational prescriptions. This is as a result of the standardized dosage plan of most pediatric HAART prescriptions with many patients getting one to three months' supply, each patient receiving a pack per month and all formulations being dosed once or twice a day [16]. This contrasts with essential medicines majority which may be dosed in the range of once to four times daily.

Errors of integration were higher than those found in studies that were conducted on essential medicines $[25,26]$ and yet were 
substantially lower than in research done for HAART [29,35-37]. It should be noted that the studies that were done for HAART comprised both adult and child participants. Incomplete regimens were fairly common in prescriptions in other studies compared to the $3 \%$ in this study. Several studies have attributed prescription of incomplete regimens to patients not providing adequate information about their medicines on presenting to clinics attesting to the need for continuity in documentation [31,38,39]. This is provided for by the nature of ART records ('HIV care/ART continuation card') in the Ugandan HIV care and treatment program. In addition, provision of FDC formulations is also vital in reducing the risk of receiving incomplete regimens. Pastakia et al found that patients on non-FDCs were almost twice as likely to receive incomplete regimens as those on FDCs [40].

It is also of note that $57.8 \%$ of the children did not have a CD4 test done during the study period within range of the $55.9 \%$ and $64.8 \%$ found in other studies [41,42]. This contravened the treatment guidelines which recommended a minimum of one CD4 test in six months to monitor treatment response [16]. Each child who did not receive a test in the review period could potentially have been receiving an irrational prescription making the proportion of these prescriptions even higher.

\section{Factors Associated with Irrational Prescriptions}

Being on treatment for less than a year was associated with having at least one irrational prescription. Of particular concern is that the median age of these new patients at initiation was six years. These children do not have well-developed excretory systems making any irrational prescriptions harmful. Furthermore, any adverse events that are experienced by new patients are likely to deter them from continuing with treatment leading to treatment interruption and potentially drug resistance. To the best of our knowledge, this is the first study that has demonstrated that treatment-naïe patients are more likely to have an irrational prescription than their experienced counterparts.

There were more patients with irrational prescriptions in the private than the public sector. This is consistent with findings in several systematic reviews and medicines policy evaluations that have highlighted that the private sector faces particular challenges in adhering to guidelines $[33,43,44]$. Majority of these findings were focused on essential medicines and therefore it is plausible that private facilities were targeting higher profit margins. However, ARVs are provided free of charge in most clinics in Uganda. As profit is not a motive, other factors were probably responsible for the high prevalence of patients with irrational prescriptions in TASO.

One of these factors could be the size of the clinic. This facility had almost three times the number of patients compared to Iganga hospital. The average number of health workers assigned to a clinic in TASO was nine contrasted with seven in Iganga. A systematic review that projected the number of health care workers needed to run a HAART clinic in a resource-limited setting suggested between 8.5 and 10 personnel for every 1,000 patients [45]. TASO consequently required at least six times the number of health workers it had based on its patient population. It should also be noted that these estimates refer to HAART only. Prescribers in health centers will typically attend to both pre-ART and ART patients and as such, the need for additional staff becomes greater. This corroborates with findings in Uganda where prescribers admitted to being too busy to reference treatment guidelines [46].

Secondly, lack of access to key medicines and equipment have played a role in irrational prescribing. 89\% of the children who did not have a CD4 test within the study period were from TASO and this could have been because they did not have a CD4 machine on site. Much as the CD4 machine was not far from the health facility, Point of Care testing platforms should be provided to high volume health centers to reduce the number of patients who might miss a test. Nevertheless, health workers need to be encouraged to use these monitoring tests. Only $10 \%$ of children who were started on a Zidovudine-based regimen received a hemoglobin test and 5 children did not have weight taken at all their visits despite hemoglobinometers and weighing scales being available at both facilities.

\section{Limitations of the study}

This study was conducted in two purposively selected urban health facilities and may not be representative of other facilities nationwide. Furthermore, the study assessed a period of 6 months. It would be difficult to identify treatment failure or any related adherence problems and therefore the need to switch a regimen in such a short period of time. Other drugs prescribed that might have been contraindicated with the children's HAART regimen were not assessed.

\section{Conclusion}

The prevalence of irrational prescriptions in Uganda is high. Children receiving care in private health facilities and those newly initiated on treatment are at particularly high risk of receiving these prescriptions. Knowledge gaps amongst prescribers must be addressed through quality improvement strategies including mentorship, clinic audits, pharmacy reviews and automated prescribing systems where possible. Future research should identify whether children receive these irrational prescriptions at the dispensing point and the impact of such prescriptions on virologic control and the cost of care.

\section{Acknowledgements}

I would like to thank the following for their support:

- Dr. Jessica Nakiyiingi-Miiro for dedicating her time to advise me

- The staff especially the prescribers and the pharmacy staff at TASO Jinja and Iganga hospital for being accommodating 
- My research assistants for their hard work on this project

- My co-authors for their guidance and patience with all my questions

- My employer Clinton Health Access Initiative and supervisors for the willingness to give me time off

- My family and friends for their moral and financial support

- Last but not least, to the Almighty God for the blessings he bestows upon me daily

\section{References}

1. UNAIDS (2015) UNAIDS Fact Sheet. Geneva, Switzerland 2015.

2. UNAIDS (2015) Uganda Data. Accessed 9 March 2016.

3. amfAR - Making AIDS History (2016) Worldwide statistics 2015. Accessed 9 March 2016.

4. UNAIDS (2015) The HIV and AIDS Uganda Country Progress Report 2014. Kampala, Uganda.

5. van Dijk JH, Sutcliffe CG, Munsanje B, Sinywimaanzi P, Hamangaba F, et al. (2011) HIV-Infected Children in Rural Zambia Achieve Good Immunologic and Virologic Outcomes Two Years after Initiating Antiretroviral Therapy. PLoS ONE 6: e19006.

6. Musoke PM, Mudiope P, Barlow-Mosha LN, Ajuna P, Bagenda D, et al. (2010) Growth, immune and viral responses in HIV infected African children receiving highly active antiretroviral therapy: a prospective cohort study. BMC Pediatr 10: 56.

7. Banerjee T, Pensi T, Banerjee D, Grover G (2010) Impact of HAART on survival, weight gain and resting energy expenditure in HIV-1-infected children in India Ann Trop Paediatr 30: 27-37.

8. Sophan S, Meng CY, Pean P, Harwell J, Hutton E, et al. (2010) Virologic and Immunologic outcomes in HIV-infected Cambodian children after 18 months of Highly Active Antiretroviral Therapy (HAART). Southeast Asian J Trop Med Public Health 41: 126-37.

9. Edmonds A, Yotebieng M, Lusiama J, Matumona Y, Kitetele F, et al. (2011) The effect of highly active antiretroviral therapy on the survival of HIV-infected children in a resource-deprived setting: a cohort study. Plos Med 8: e1001044.

10. UNAIDS (2010) Global Report: UNAIDS Report on the Global AIDS Epidemic 2010. Geneva, Switzerland.

11. WHO, UNAIDS, UNICEF (2011) Global Summary of the AIDS Epidemic 2011. Accessed 31 March, 2014.

12. WHO (2012) The Pursuit of Responsible Use of Medicines: Sharing and Learning from Country Experiences. Technical report prepared for the ministers' summit on the benefits of responsible use of medicines: Setting policies for better and cost-effective health care. Geneva, Switzerland 2012.

13. Holloway K, Van Dijk L (2011) The World Medicines Situation 2011. Geneva, Switzerland.

14. WHO (1985) The Rational Use of Drugs. Report of the Conference of Experts. Geneva, Switzerland.

15. Hogerzeil HV (1995) Promoting rational prescribing: an international perspective. Br J clin Pharmac 39: 1-6.

16. Ministry of Health (2012) The Integrated National Guidelines on Antiretrovial Therapy, Prevention of Mother to Child Transmission of HIV and Infant and Young Child Feeding, Kampala, Uganda.

17. Turkova A, Webb RH, Lyall H (2012) When to Start, What to Start and Other Treatment Controversies in Pediatric HIV Infection. Pediatr Drugs 14: 361-76. 18. Ponnet M, Frederix K, Petdachai W, Wilson D, Eksaengsri A, et al. (2005) A drug dosage table is a useful tool to facilitate prescriptions of antiretroviral drugs for children in Thailand. Int J STD AIDS 16: 420-6.

19. Suárez-García I, Sobrino-Vegas P, Tejada A, Viciana P, Ribas M, et al. (2014) Compliance with national guidelines for HIV treatment and its association with mortality and treatment outcome: a study in a Spanish cohort. HIV Med 15: 86-97.

20. Tourret J, Tostivint I, Tézenas Du Montcel S, Karie S, Launay-Vacher V, et al. (2007) Antiretroviral Drug Dosing Errors in HIV-Infected Patients Undergoing Hemodialysis. Clin Infect Dis 45: 779-84.

21. DeLorenze GN, Follansbee SF, Nguyen DP, Klein DB, Horberg M, et al. (2005) Medication Error in the Care of HIV/AIDS Patients: Electronic Surveillance, Confirmation, and Adverse Events. Med Care 43: III63-8.

22. Kaushal R, Jaggi T, Walsh K, Fortescue EB, Bates DW (2004) Pediatric Medication Errors: What Do We Know? What Gaps Remain? Ambul Pediatr 4: 73-81.

23. Hellinger F, Encinosa W (2010) The Cost and Incidence of Prescribing Errors Among Privately Insured HIV Patients. Pharmacoeconomics 28: 23-34.

24. Maat B, Au YS, Bollen CW, van Vught AJ, Egberts TC, et al. (2013) Clinical pharmacy interventions in paediatric electronic prescriptions. Arch Dis Child 98: $222-7$.

25. Vila-de-Muga M, Colom-Ferrer L, Gonzalez-Herrero M, Luaces-Cubells C (2011) Factors Associated With Medication Errors in the Pediatric Emergency Department. Pediatr Emerg Care 27: 290-4.

26. Al Khaja KA, Al Ansari TM, Damanhori AH, Sequeira RP (2007) Evaluation of drug utilization and prescribing errors in infants: A primary care prescriptionbased study. Health Policy 81: 350-7.

27. Ferner RE, Aronson JK (1999) Errors in prescribing, preparing, and giving medicines: definition, classification, and prevention. In: Aronson JK, Elis J, eds. Side Effects of Drugs Annual. Elsevier xxiii-xxxvi.

28. Menson EN, Walker S, Sharland M, Wells C, William GT, et al. (2006) Underdosing of antiretrovirals in UK and Irish children with HIV as an example of problems in prescribing medicines to children, 1997-2005: cohort study. BMJ 332.

29. Agu KA, Oqua D, Adeyanju Z, Alfa Isah M, Adesina A, et al. (2014) The Incidence and Types of Medication Errors in Patients Receiving Antiretroviral Therapy in Resource-Constrained Settings. PLoS ONE 9: e87338.

30. Ghaleb MA, Barber N, Franklin BD, Wong ICK (2010) The incidence and nature of prescribing and medication administration errors in paediatric inpatients. Arch Dis Child 95: 113-8.

31. Commers T, Swindells S, Sayles H, Gross AE, Devetten M, et al. (2014) Antiretroviral medication prescribing errors are common with hospitalization of HIVinfected patients. J Antimicrob Chemother 69: 262-7.

32. van Rosse F, Maat B, Rademaker CM, van Vught AJ, Egberts AC, et al. (2009) The Effect of Computerized Physician Order Entry on Medication Prescription Errors and Clinical Outcome in Pediatric and Intensive Care: A Systematic Review. Pediatrics 123: 1184-90.

33. Basu S, Andrews J, Kishore S, Panjabi R, Stuckler D (2012) Comparative Performance of Private and Public Healthcare Systems in Low- and Middle-Income Countries: A Systematic Review. Plos Med 9: e1001244. 
34. Oshikoya KA, Ojo OL (2007) Medication errors in paediatric outpatient prescriptions of a teaching hospital in Nigeria. Nig Q J Hosp Med 17: 74-8.

35. Rao N, Patel V, Grigoriu A, Kaushik P, Brizuela M (2012) Antiretroviral therapy prescribing in hospitalized HIV clinic patients. HIV Med 13: $367-71$.

36. Yehia BR, Mehta JM, Ciuffetelli D, Moore RD, Pham PA, et al. (2012) Antiretroviral Medication Errors Remain High but Are Quickly Corrected Among Hospitalized HIV-Infected Adults. HIV/AIDS 55: 593-9.

37. Carcelero E, Tuset M, Martin M, De Lazzari E, Codina C, et al. (2011) Evaluation of antiretroviral-related errors and interventions by the clinical pharmacist in hospitalized HIV-infected patients. HIV Med 12: 494-9.

38. Mok S, Minson Q (2008) Drug-related problems in hospitalized patients with HIV infection. Am J Health Syst Pharm 65: 55-9.

39. Rastegar AD, Knight AM, Monolakis JS (2006) Antiretroviral Medication Errors among Hospitalized Patients with HIV Infection. Clin Infect Dis 43: 933-8.

40. Pastakia SD, Corbett AH, Raasch RH, Napravnik S, Correll TA (2008) Frequency of HIV-Related Medication Errors and Associated Risk Factors in Hospitalized Patients. Ann Pharmacother 42: 491-7.

41. Burua A, Nuwaha F, Waiswa P (2014) Adherence to standards of quality HIV/AIDS care and antiretroviral therapy in the West Nile Region of Uganda. BMC Health Serv Res 14: 521.

42. Carmody ER, Diaz T, Starling P, Santos AP, Sacks HS (2003) An evaluation of antiretroviral HIV/AIDS treatment in a Rio de Janeiro public clinic. Trop Med Int Health 8: 378-85.

43. Berendes S, Heywood P, Oliver S, Garner P (2011) Quality of Private and Public Ambulatory Health Care in Low and Middle Income Countries: Systematic Review of Comparative Studies. Plos Med 8: e1000433.

44. WHO (2009) Medicines use in primary care in developing and transitional countries. Factbook summarizing results from studies reported between 1990 and 2006. Bull World Health Organ 87: 804.

45. Hirschhorn LR, Oguda L, Fullem A, Dreesch N, Wilson P (2006) Estimating health workforce needs for antiretroviral therapy in resource-limited settings. Hum Resour Health 4:1.

46. Tumwikirize WA, Ogwal-Okeng JW, Vernby A, Anokbonggo WW, Gustafsson LL, et al. (2007)Access to up-to-date drug information in developing countries continues to pose problems: The case of Uganda. Pharmacoepidemiol Drug Saf 16: 1177-9.

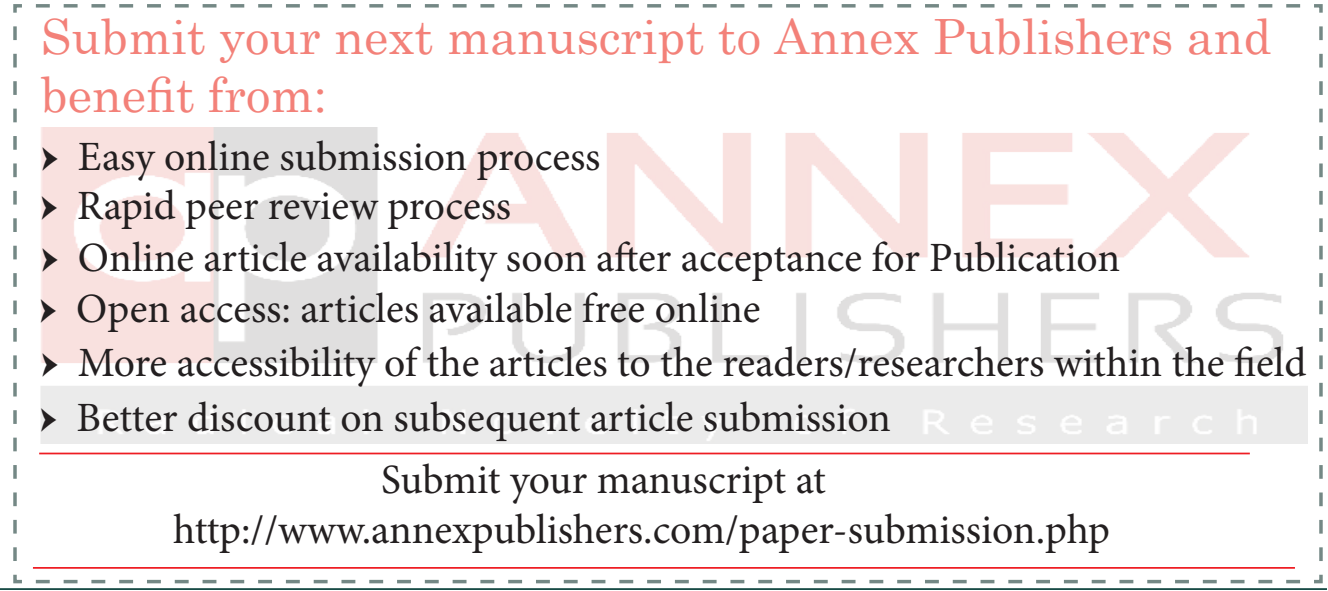

